\title{
Relationship of radiological change to clinical outcome in rheumatoid arthritis
}

\author{
ANDREW BROOK, A. FLEMING, AND MARY CORBETT \\ From the Department of Rheumatology, Middlesex Hospital, London
}

SUMMARY Ninety-four patients with rheumatoid arthritis, seen within the first year after onset have been followed prospectively with annual radiographs for a mean 63.1 months. An erosive arthropathy occurred in 72 . The severity of the erosive changes showed a significant correlatior $\omega_{5}$ with eventual clinical outcome. It is possible to predict a favourable outcome in those patients whosei erosive changes become static at an early stage in the disease.

This paper seeks to establish two clinical relationships in rheumatoid arthritis (RA) firstly, that between radiological severity and eventual clinical outcome, and secondly, that between radiological progression and clinical outcome.

The appearance of early erosions in rheumatoid arthritis correlates with a worse prognosis (Fleming et al., 1975). Common sense would suggest that the more severe the subsequent erosive disease the worse is the eventual clinical state, though this has not yet been quantified. Indeed, exceptions to this appear in the literature (De Haas et al., 1974), the so called 'robust rheumatoids', where good function is maintained despite an extensive erosive arthropathy.

A prospective study of early RA has given us the opportunity to examine the relationship between radiological severity and clinical outcome. In an earlier paper (Brook and Corbett, 1977) we described the $x$-ray changes in early rheumatoid arthritis and found that our patients fell into two groups as assessed by progression of erosive changes, namely 'static' and 'progressive'. We are now able to report on the relationship between these two groups and their subsequent clinical status.

\section{Patients and methods}

The material for this paper is taken from the Middlesex Hospital Prospective Study of Early

Accepted for publication August 19, 1976

Present addresses: A.B.: Woden Valley Hospital, Canberra, ACT 2606, Australia. A.F.: Prince Henry and Prince of Wales Hospitals, Sydney, New South Wales, Australia.

Correspondence to Dr. M. Corbett, Department of Rheumatology, Middlesex Hospital, Arthur Stanley House, Tottenham St., London W1P 9PG.
Rheumatoid Disease (Fleming et al., 1975, 1976) The radiological features of this study have already been described (Brook and Corbett, 1977). Briefly 94 patients with RA presenting within the first yeak of onset (mean 7.9 months) were followed prospec ${ }^{-}$ tively with annual radiographs of hands and feet. The sample included 41 men and 53 women, means age at onset $48 \cdot 9$ years. Mean radiological follow-upo was $63 \cdot 1$ months. Severity of $x$-ray change was assessed by totalling of point scores for the exten $B$ of involvement at individual sites, total number of erosions, and degree of osteoporosis. For analysis the cases have been divided into four groups: non erosive, mild, moderate, and severe. It was alsợ? possible to divide the patients into 'progressive (those in whom erosions continued to enlarge op appear at new sites) and 'static'.

Clinical data were gathered prospectively every months for a mean follow-up of 53 months. The patients were divided into three prognostic categories on the basis of functional grade, extent of joinf involvement, grip strength, and duration of earlys morning stiffness (Fleming et al., 1976). These categories were 'improved', 'mild', and 'severe', but for the purpose of this analysis the first two have been considered together as 'mild'.

Clinical and radiological assessments were perês formed independently.

\section{Results}

CLINICAL ASSESSMENT Of the 94 patients, 55 had persistently severe on deteriorating disease and 39 had improved or pursued a much milder course. 
RADIOLOGICAL SEVERITY

25 patients were judged to show severe changes, 25 moderate, and 22 mild. 22 had no erosive change.

\section{RADIOLOGICAL PROGRESS}

36 of the erosive cases showed progressive changes. The remaining 36 erosive cases became static at a mean $22 \cdot 1$ months from the onset of joint symptoms, 29 of them within the first 2 years. The 22 nonerosive cases were regarded as static.

\section{ANALYSIS}

The relationship of radiological severity to clinical outcome is shown in Table 1. There was an obvious trend for the milder clinical cases to be milder radiologically. In fact, there is no statistically significant difference between 'nonerosive' and 'mild', nor between 'moderate' and 'severe'. If, however, we combine 'moderate and severe' (50 patients) and compare it with 'nonerosive and mild' (44 patients), the relationship is highly significant $\left(\chi^{2}=33 \cdot 25\right.$, $\mathbf{P}<0.001$ ). The relationship of radiological severity to clinical outcome is shown in Table 2 . This is also highly significant $\left(\chi^{2}=14 \cdot 81, P<0 \cdot 001\right)$.

Table 1 Comparison of clinical severity and radiological severity ( 94 patients)

\begin{tabular}{lll}
\hline & Clinically mild & Clinically severe \\
\hline Radiologically & 18 & 4 \\
$\quad$ nonerosive & 14 & 8 \\
Mild & 5 & 20 \\
Moderate & 2 & 23 \\
Severe & & \\
\hline
\end{tabular}

Table 2 Comparison of clinical severity and radiological progress (94 patients)

\begin{tabular}{lll}
\hline & Clinically mild & Clinically severe \\
\hline $\begin{array}{l}\text { Radiologically } \\
\text { static }\end{array}$ & 33 & 25 \\
$\begin{array}{c}\text { Radiologically } \\
\text { progressive }\end{array}$ & 6 & 30 \\
\hline
\end{tabular}

\section{Discussion}

These results indicate clearly the relationship between an erosive arthropathy and eventual clinical status. It is of fundamental importance in RA that the occurrence of erosions strongly indicates a poor prognosis as measured by clinical variables with a bias towards joint function. The more severe these radiological changes, the more likely the patient is to have a poor outcome. This study gives quantitative support to this commonsense concept.

The identification (Brook and Corbett, 1977) of a subgroup of erosive patients who could become radiologically 'static' within the first few years of joint symptoms was of interest, and we have now been able to assess the subsequent clinical course of this subgroup. Though none of these patients regained radiological normality, their clinical status was much better at the end of the follow-up period than those whose erosive arthropathy was progressive. Thus quiescence of clinical signs and symptoms may be reflected early in the $x$-ray.

We thank Drs. O. Savage, A. C. Boyle, S. Mattingly, and D. Woolf for allowing us to study their patients. Statistical advice was received from the ARC Epidemiology Research Unit, Manchester, under the direction of Dr. P. H. N. Wood, and from Miss S. Chin, Clinical Research Centre, Harrow. Professor I. M. Roitt provided encouragement and advice. The study has been generously supported by the Arthritis and Rheumatism Council.

\section{References}

Brook, A. S., and Corbett, M. (1977). Radiographic changes in early rheumatoid disease. Annals of the Rheumatic Diseases 36, 71-73.

De Haas, W. H. D., De Boer, W., Griffioen, F., and OostenElst, P. (1974). Rheumatoid arthritis of the 'robust reaction type'. Annals of the Rheumatic Diseases, 33, 81-85.

Fleming, A., Corbett, M., and Crown, J. M. (1975). The relationship of early features to prognosis in rheumatoid disease. Scandinavian Journal of Rheumatology, Suppl. 8, 032.

Fleming, A., Dodman, S., Crown, J. M., and Corbett, M. (1976). Extra-articular features in early rheumatoid disease. British Medical Journal, 1, 1241-1243. 